\title{
The Role of Economic and Political Features in Classification of Countries- in-Transition by Human Development Index
}

\author{
Jani KINNUNEN ${ }^{1}$, Armenia ANDRONICEANU ${ }^{2}$, Irina GEORGESCU ${ }^{2}$ \\ ${ }^{1}$ Abo Akademi, Turku, Finland \\ ${ }^{2}$ Bucharest University of Economic Studies, Romania \\ jkinnune@abo.fi, armenia.androniceanu@man.ase.ro, irina.georgescu@csie.ase.ro
}

Typical classification research of the United Nations' Human Development Index, HDI, has focused on its direct underlying sub-indices, i.e., Gross National Income, GNI, Education and Health. In this paper, economic and political systems within which the elements of HDI are created are under study. We use Bertelsmann Foundation's qualitative data from period 20082016 on 124 countries-in-transition including features of market economy, democracy and governance. The purpose is to identify the most important economic and political features predicting the level of HDI and to compare the classification performances of the applied models: an artificial neural network, ANN, and a logistic regression. The multi-method approach is complemented by multiple correspondence analysis for descriptive analysis purposes. The main results and original contributions include proving the effectiveness of the ANN over the logistic regression and showing that the higher levels and specific individual factors of marked economy, governance and democracy, the higher the HDI.

Keywords: Artificial Neural Network, Democracy, Governance, Human Development Index, Logistic Regression Multiple Correspondence Analysis, Market Economy

\section{1} Introduction

The real wealth of a nation arises from its population and the its productive actions taking place in an economic system, which is based on institutions and rules affected by political system with governing decision-makers. The goal of economic development is to create an environment that will provide people with a long life and a good living standard and to improve peoples' lives[1, 2]. Individuals have subjective expectations in terms of better life [3] and they pursue to it through exchange in market-economy system [4]. Growth and human development ensure the quality of life and they are interdependent and complementary $[5,6]$.Therefore, using the outcomes of economic growth to increase the level of sustainable human development calls for special attention [7]. The 2011 Human Development Report [8] shows that the global challenges of sustainable development and economic growth need to be considered together, and governments have to cooperate with the business community to provide better living standards. Economic freedom is a feature of market economy. It means encouraging entrepreneurial activities, protecting property rights, freedom of exchange, reducing the size of governments, and lowering government expences. The relationship between economic freedom and human development is clear, when we look at the Economic Freedom Index and the Gross National Income (GNI) per capita: the more economic freedom, the higher the economic performance $[9,10]$. Using GNI per capita, as an indicator of economic performance is argued being more appropriate than using GDP per capita $[11,12]$.

The United Nations' Human Development Index (HDI) takes into account several dimensions to qualify a country as strong, medium or poorly developed [13]. HDI has three main dimensions of human development: (1) a long and healthy life, measured by life expectancy at birth; (2) knowledge: measured by the adult literacy rate and by enrollment in primary, secondary and tertiary education; (3) a decent living standard: represented by GNI per capita. HDI is a standardized measure of well-being, used to determine whether a country is developed, developing or underdeveloped, as 
well as, to measure the impact of economic policies on quality of life. Its purpose has been to work as a reference framework for both economic and social development. Analysis of the HDI highlights the existence of economic and social disparities between developed and developing countries and allows the identification, definition and implementation of government policies needed to reduce the gaps [14].

HDI covers limited areas, which are not necessarily related and complementary. For example, a high level of literacy and enrolment in education does not necessarily mean a high value of GNI. For comparison, the Economic Freedom Index (EFI) covers broader areas. EFI measures freedom as a precondition for development, while HDI focuses on human development as the ultimate goal, regardless of the factors contributing to it $[15,16]$. The high scores for some of the indexes that make up it are consistent with a high degree of government intervention [17] and, for example, the countries with high scores on the education index have the highest shares of GNI spent on education. It is obvious that the components (1)-(3) of HDI are its very good predictors, but national income level (3) has been found the most important one followed by education level (2) and life-expectancy, in this order [18].

Using the direct component of HDI, neural network modelling has shown over $95 \%$ accuracy in predicting the level of HDI, while classical linear regression has reached an accuracy level of $90 \%$ [19]. In general, the prediction capability of neural networks has been shown superior over other methods in several studies and application environments [20, 21, 22, 23, 24]. Some recent research has focused on HDI, for example, Connoly et al. [25] apply the logistic regression to study the predictors that lead to a probability of high HDI: GDP per capita, the number of schooling years and life expectancy. Their investigation shows that an increase in the expected years in education most likely will contribute to a very high level of HDI. Saboo et al [26] compare ANNs and multilinear regression accuracy in predicting HDI based on four predictors: mean years of schooling, average years of schooling, GNI per capita and life expectancy at birth. The experiment showed that ANNs accuracy was better, 95\%.

HDI has its limitations as an indicator of development, but it is widely used and factors affecting it are of major interest for policy makers [18]. Market-economy system based on free exchange requires rules and they are affected by political systems within which decision-makers govern. In this paper, the purpose is to take into account these perspectives ranging from the status and characteristics of existing market-economy system, level of democracy, and the capability of decision-makers in their difficult environment, and their impact on HDI.

In section 2, the used data variables are described and discussed. Section 3 applies the chosen methods, firstly in 3.1, the HDI categories of the 124 countries-in-transition are described by using multiple correspondence analysis, MCA, to analyze the correlations of categorical aggregate-level indices built on the features of market economy, democracy, governance quality and difficulty. To broaden the picture, we include also factors determining the difficulty level, i.e., the UN's education index and gross national income index, the two direct underlying factors of HDI. In section 3.2, an artificial neural networks approach is used to find out the most important factors predicting HDI categories. Section 3.3 uses logistic regression to withdraw another perspective to the relation of economic and political features and HDI. The predictive power of the models and other results are discussed in comparison in the concluding section 4.

\section{Data}

Bertelsmann Foundation's most recent data from 2018 [27] depicting the situation as of January 2017 is used together with United Nation's human development index, HDI, for the period 2008-2016 [13] (table 1). The Bertelsmann variables evaluate three aspects: political, economic, and governance quality. 
Table 1. Description of variables

\begin{tabular}{|c|c|}
\hline Variable & Criteria \\
\hline \multicolumn{2}{|r|}{ Aggregate indicators for MCA } \\
\hline ME - Market economy & ME averages the factors of political system, V6-V12. \\
\hline DEM - Democracy & DEM averages the factors of political system, V1-V5. \\
\hline BTI - Bertelsmann Index & $\begin{array}{l}\text { The Bertelsmann transformation index averages the underlying } \\
\text { political, V1-V5, and economic, V6-12, indicators. BTI is a } \\
\text { combination of ME and DEM. [27] }\end{array}$ \\
\hline GOV - Governance Index & $\begin{array}{l}\text { The governance index weighs the quality indicators, V14-V17, } \\
\text { by difficulty levels underlying V13. [27] }\end{array}$ \\
\hline DIF - Difficulty Index & DIF measures the difficulty of the operating environment [27]. \\
\hline GNI - Income Index & $\begin{array}{l}\text { The UN's gross national income of its production less the cost } \\
\text { of used factors of owned by others. Atlas scaled index. [27] }\end{array}$ \\
\hline EDU - Education Index & The UN's rescaled education index [27] \\
\hline $\begin{array}{l}\text { HDI, human development } \\
\text { index }\end{array}$ & $\begin{array}{l}\text { United Nation's composite index measuring human develop- } \\
\text { ment by the three dimensions: 1) life expectancy, 2) education } \\
\text { and } 3 \text { ) standard of living (GNI). The dependent variable is di- } \\
\text { vided into categories: high, medium, low and very low [13] }\end{array}$ \\
\hline \multicolumn{2}{|r|}{ Political features } \\
\hline V1 - Stateness & Clarity of state's existence with established structures. \\
\hline V2 - Political Participation & Extent of general, free and fair elections and political liberties. \\
\hline V3 - Rule of Law & Extent of separation of powers and civil rights. \\
\hline $\begin{array}{l}\text { V4 - Stability of Demo- } \\
\text { cratic Institutions }\end{array}$ & Capability and acceptance of existing democratic institutions. \\
\hline $\begin{array}{l}\text { V5 - Political and Social } \\
\text { Integration }\end{array}$ & $\begin{array}{l}\text { Level of representative meditation between society and the } \\
\text { state. }\end{array}$ \\
\hline \multicolumn{2}{|r|}{ Economic features } \\
\hline $\begin{array}{l}\text { V6 - Level of Socio-eco- } \\
\text { nomic Development }\end{array}$ & $\begin{array}{l}\text { Level of lack of poverty and inequality, which exclude people } \\
\text { from society and don't permit freedom of choice for all citizens. }\end{array}$ \\
\hline $\begin{array}{l}\text { V7 - Organization of the } \\
\text { Market and Competition }\end{array}$ & Level of clear rules for stable market-based competition. \\
\hline $\begin{array}{l}\text { V8 - Currency and Price } \\
\text { Stability }\end{array}$ & $\begin{array}{l}\text { Extent of institutional precautions to control inflation sustaina- } \\
\text { bly with appropriate monetary and fiscal policies. }\end{array}$ \\
\hline V9 - Private Property & Extent of property rights to support a functional private sector. \\
\hline V10 - Welfare Regime & $\begin{array}{l}\text { Extent of equal opportunities and social safety nets to compen- } \\
\text { sate for social risk of unemployment, poverty and illness. }\end{array}$ \\
\hline $\begin{array}{l}\text { V11 - Economic Perfor- } \\
\text { mance }\end{array}$ & $\begin{array}{l}\text { Level of economic performance based on quantitative measures } \\
\text { such as GDP, inflation, unemployment, FDI, public debt, etc. }\end{array}$ \\
\hline V12 - Sustainability & $\begin{array}{l}\text { Level of sustainable growth based on education, research and } \\
\text { development, and environmentally sustainable policies. }\end{array}$ \\
\hline \multicolumn{2}{|r|}{ Governance features } \\
\hline V13 - Steering Capability & Capability of governance to prioritize and implement policies. \\
\hline V14 - Resource Efficiency & $\begin{array}{l}\text { Efficient use of resources in anti-corruption policy environ- } \\
\text { ment. }\end{array}$ \\
\hline V15 - Consensus-Building & Level of governance's consensus-building within society. \\
\hline $\begin{array}{l}\text { V16 - International Co- } \\
\text { operation }\end{array}$ & Level of governance's ability to co-operate with external actors. \\
\hline
\end{tabular}


Table 1 describes first the aggregate-level variables, which are mainly used for descriptive purposes. They are built on the following variables, V1-V16, except the dependent variable, HDI.

1) the political indicators measure the state of political transformation in terms of five criteria, V1-V5, based on expert assessment of 18 underlying questions (excluded here). Each five criteria have further underlying variables of which are weighted by averaging. V1, Stateness, measures specifically state's monopoly on the use of force and is viewed as a precondition to democracy, V2 deals with general political liberties, V3 focuses on the separation of powers, V4 deals with general quality and acceptance of exiting political institutions, while V5 measures representativeness of the institutions;

2 ) the economic indicators measure the state of transformation towards market economy in terms of seven criteria, V6-V12, which are further built on 14 underlying indicators (not included here although some are pointed out for their importance of later interpretations of results). These take into account the freedom of choice not limited by poverty, V6, rules of competition, V7, stability of monetary and fiscal policies, V8, property rights, V9, equal opportunity based on safety nets, V10, economic performance, V11, sustainable growth, V12;

3 ) the governance indicators, V13-V16, are further built on individual indicators. Bertelsmann data also uses difficulty level (DIF in table 1) as a governance indicator as weight for governance quality measured by V14-V17 to get the Bertelsmann's governance index, BTI. Data for the difficulty include structural difficulties, traditions and conflicts in society all based on expert evaluations, but it further includes comparable measures for education and GNI, the UN's education index., and also rule of law. We use these difficulty-related variables only for descriptive purposes and exclude them from neural network and logistic regressions as they have direct underlying variables of HDI, while our goal is to focus on the political and economic features, which allow development measured by income, education and health. V13 measures the capability of policymakers, V14 the efficiency in the use of resources, and V15 the co-operation in decision-making within a country, while V17 reflects the co-operation with foreign actors.

\section{Methods and Analysis}

\subsection{Description of HDI Classes and Multi- ple Correspondence Analysis (MCA)}

Following [28], the multiple correspondence analysis is conducted with $\mathrm{R}$ software to find the related high-level factors characterizing countries and to reveal their importance in explaining the variations in the data. MCA is a principal component method applicable to qualitative, categorical, data. Dimensions represent principal components, which are ordered so that the first and second ones (Dim1 and Dim2 in figures 1 and 2) explain most of the variation of the data. In MCA, the indicator matrix is used and associations between variables are uncovered by calculating distances between the variable categories, as well as, between countries. The associations are visualized and interpreted. We use categorical data based on Bertelsmann's classification ("aggregate" variables in Table 1) for market economy (ME based on V6-V12), democracy (DEM based on V1-V5), their combination (BTI combining DEM \& ME based on V1V12 and corresponding the actual Bertelsmann Transformation Index), governance (GOV based on V14-V16), the level of environmental difficulty to govern (DIF based on V13), and the four categories of the UN's human development (HDI) and national income index (GNI, Atlas-scaled) and UN's education index (EDU).

The United Nations [13] classifies countries in four categories according to four intervals of HDI: low (0-0.499), medium (0.500-0.799), high (0.800-0.899) or very high (greater than $0.900)$. Here, instead classify countries into following four classes: very low $(0-0.520)$, low (0.521-0.678), medium (0.679-0.768), and high (greater than 0.769 ) based on the calculated quartile levels from our sample. As our sample of 124 consists of countries-intransition, we do not have countries belonging 
to the UN's very high class except Singapore with its HDI of 0.91 (cf. tables 2-5).

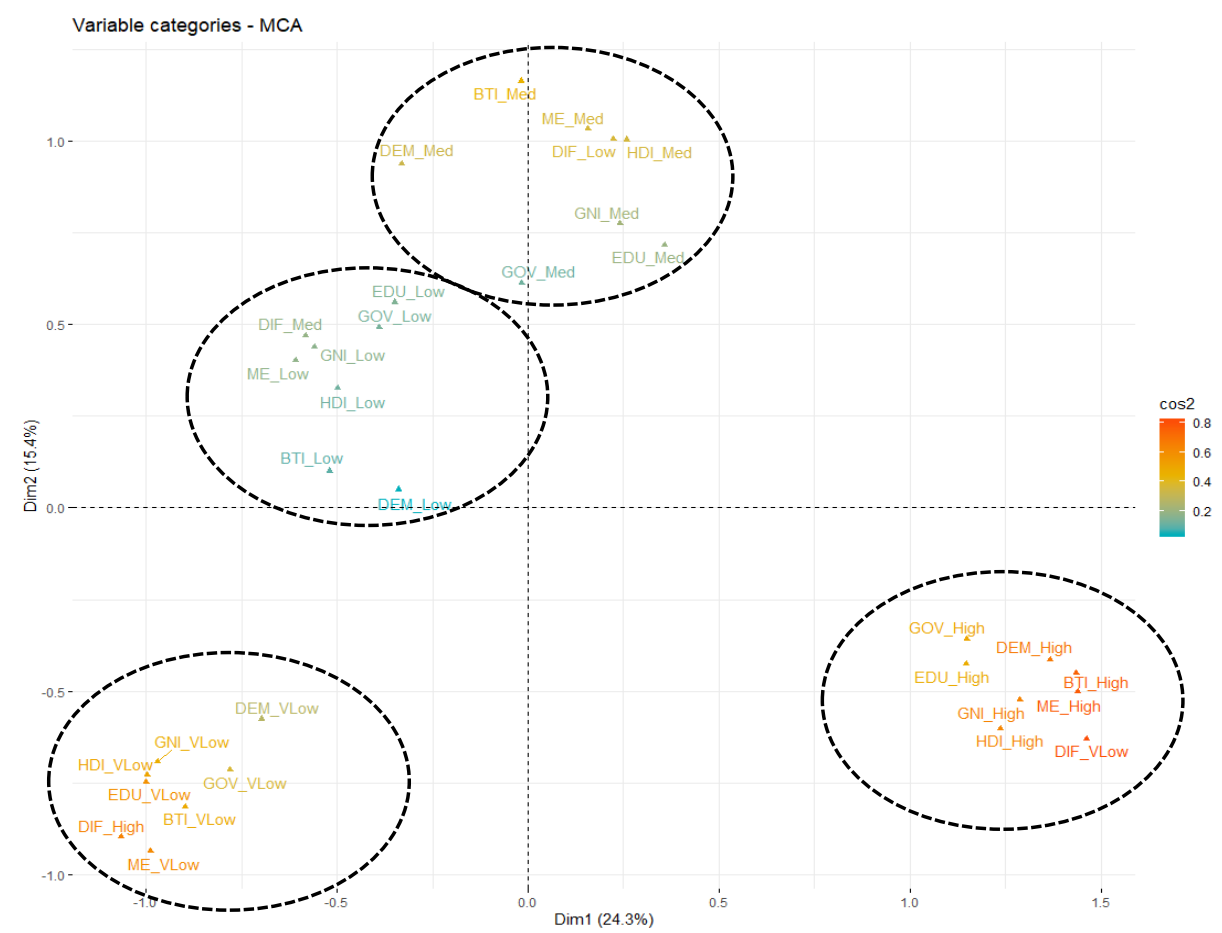

Fig. 1. MCA and aggregate variable classes: HDI, ME, DEM, BTI, GOV, DIF, EDU and GNI

Figure 1 shows all the classes of the aggregate variables HDI (range 0-1), ME, DEM, BTI (DE\&ME), GOV (all ranging from 0 to 10 ), DIF, GNI, and EDU (ranging from 0 to 10, but in reversed order, i.e., the lower the index value, the better). The largest contributions (measured by their correlation, $\cos 2$, with the two dimensions) are depicted from largest (red) to lowest (blue). The variable classes are clustered together very clearly. Without exceptions, high classes of HDI, ME, DEM, BTI, GOV, DIF, GNI and EDU are clustered together with very low DIF, and the same applies to medium, low and very low categories (the difficulty level rising, when other variables get lower). The horizontal axis of figure 1 measures the variables' contribution to the first component (Dim1) of MCA, which explains $24.3 \%$ of total variability of the $X$ variables (which have Y-Z classes each), while the vertical axis measures the contribution to the second most important component (Dim2) explaining $15.4 \%$ of the total variability.In Figure 2, countries are positioned on the same two dimensions. It is seen that the largest correlations $(\cos 2)$ with the dimensions are found on the bottom-right corresponding the highclass countries with the lowest difficulty level, on the top corresponding to mediumclass countries, on the bottom-left corresponding to very low-class countries with the highest difficulty level. The countries seen in figure 2 are related to the variable classes positioned similarly in the two-dimensional space (Figure 1), so, they are close to each other; the variable classes can be seen as features describing the countries grouped close to each other. 


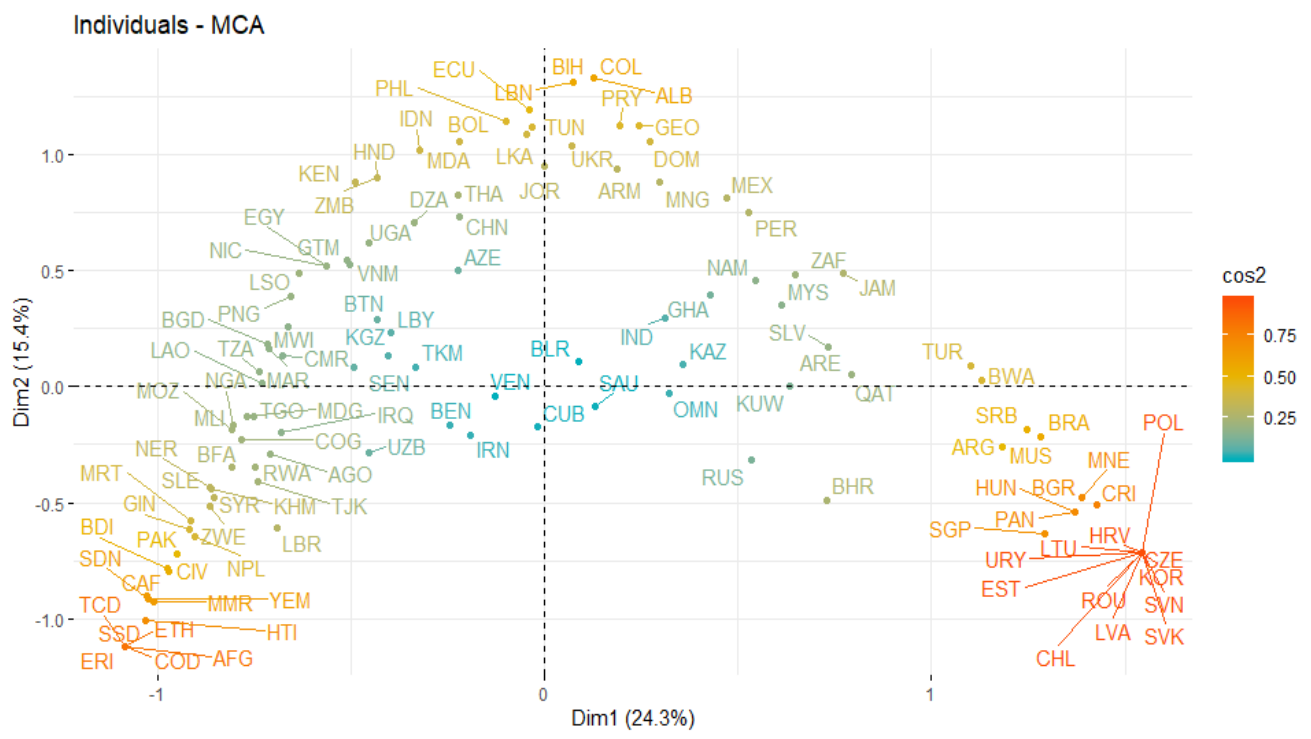

Fig. 2. MCA and the 124 countries-in-transition

The countries in the four HDI groups are described using the aggregate variable classes.

The high-level group dominated by the bottom-right quadrant is related to highly advanced democracy and market economy (the highest class of the Bertelsmann index, BTI) with negligible difficulty of the acting environment (related to difficulties to govern, traditions in society, and social, ethnic and religious conflicts). The 31 countries belonging to this group are shown in table 2 ordered by HDI values. The average HDI is 0.82 ; The average market economy and democracy combination, BTI, is 7.1 (ME: 7.5, DEM: 6.8), and the average of governance quality, GOV, is 5.6. The mean difficulty index, DIF, is very low (3.0) supported by high GNI (avg: 2.1) and high education (avg: 1.7).

Table 2. Countries with High HDI category

\begin{tabular}{|l|c|c|l|c|c|}
\hline Country & ID & HDI & Country & ID & HDI \\
\hline Singapore & SGP & 0,91 & Bahrain & BHR & 0,81 \\
South Korea & KOR & 0,89 & Oman & OMN & 0,80 \\
Slovenia & SVN & 0,88 & Romania & ROU & 0,80 \\
Czech Republic & CZE & 0,87 & Montenegro & MNE & 0,80 \\
Estonia & EST & 0,86 & Belarus & BLR & 0,80 \\
United Arab Emirates & ARE & 0,85 & Kuwait & KUW & 0,80 \\
Qatar & QAT & 0,84 & Russia & RUS & 0,79 \\
Poland & POL & 0,84 & Bulgaria & BGR & 0,79 \\
Lithuania & LTU & 0,84 & Uruguay & URY & 0,79 \\
Slovakia & SVK & 0,84 & Malaysia & MYS & 0,78 \\
Latvia & LVA & 0,83 & Kazakhstan & KAZ & 0,78 \\
Saudi Arabia & SAU & 0,83 & Cuba & CUB & 0,77 \\
Hungary & HUN & 0,83 & Iran & IRN & 0,77 \\
Chile & CHL & 0,82 & Panama & PAN & 0,77 \\
Croatia & HRV & 0,82 & Costa Rica & CRI & 0,77 \\
Argentina & ARG & 0,81 & \multicolumn{2}{|c|}{ Average } \\
\hline
\end{tabular}


The medium-level group is dominated by countries mainly contributing to the second dimension (Dim2). The 31 countries belonging to this group and their HDI values are seen in table 3 . They are all related to advanced democracy and market economy and mostly to high national income (GNI) and high HDI.
The average HDI of the group is 0.73 ; The average BTI is 6.0 (based on the levels of avg. ME: 6.0 and DEM: 5.9). Average governance quality (GOV: 4.9). is lower than in the first group. The difficulty level, DIF, is higher than in the first group averaging 4.8 and the income and education levels are lower (GNI: 5.1; EDU: 2.8).

Table 3. Countries with Medium HDI category

\begin{tabular}{|c|c|c|c|c|c|}
\hline Country & ID & HDI & Country & ID & HDI \\
\hline Serbia & SRB & 0,77 & Peru & PER & 0,73 \\
\hline Venezuela & VEN & 0,77 & Thailand & THA & 0,73 \\
\hline Mauritius & MUS & 0,76 & Ecuador & ECU & 0,73 \\
\hline Albania & ALB & 0,76 & Libya & LBY & 0,73 \\
\hline Mexico & MEX & 0,76 & Colombia & COL & 0,73 \\
\hline Sri Lanka & LKA & 0,75 & Jamaica & JAM & 0,72 \\
\hline Turkey & TUR & 0,75 & China & $\mathrm{CHN}$ & 0,72 \\
\hline Lebanon & LBN & 0,75 & Tunisia & TUN & 0,72 \\
\hline Georgia & GEO & 0,75 & Mongolia & MNG & 0,72 \\
\hline Azerbaijan & AZE & 0,74 & Dominican Republic & DOM & 0,71 \\
\hline Ukraine & UKR & 0,74 & Turkmenistan & TKM & 0,69 \\
\hline Bosnia and Herzegovina & $\mathrm{BIH}$ & 0,74 & Paraguay & PRY & 0,68 \\
\hline Brazil & BRA & 0,74 & Moldova & MDA & 0,68 \\
\hline Armenia & ARM & 0,74 & Uzbekistan & UZB & 0,68 \\
\hline Algeria & DZA & 0,74 & Botswana & BWA & 0,68 \\
\hline Jordan & JOR & 0,73 & \multicolumn{2}{|l|}{ Average } & 0,73 \\
\hline
\end{tabular}

The low-level group of countries and their features also mainly contribute to the second component (Dim2). The 31 countries and the HDI values in this group seen table 4 . They are characterized by market economy with functional flaws and defective democracy. They have less able governances, which face serious difficulties. The average of HDI is
0.60; BTI is 5.1 (ME: 5.0; DEM: 5.3); GOV: 4.6. The difficulty (DIF: 6.2 ) is much higher than in the first two groups, while average income (GNI: 7.5) and education (EDU: 6.0) levels are far lower (reminding that the GNI and EDU indices are in reversed order compared to other aggregate indices).

Table 4. Countries with Low HDI category

\begin{tabular}{|c|c|c|c|c|c|}
\hline Country & ID & HDI & Country & ID & HDI \\
\hline Philippines & PHL & 0,68 & India & IND & 0,60 \\
\hline Egypt & EGY & 0,68 & Bhutan & BTN & 0,58 \\
\hline Indonesia & IDN & 0,67 & Congo Republic & $\mathrm{COG}$ & 0,57 \\
\hline El Salvador & SLV & 0,67 & Ghana & GHA & 0,57 \\
\hline Vietnam & VNM & 0,67 & Laos & LAO & 0,57 \\
\hline South Africa & $\mathrm{ZAF}$ & 0,67 & Bangladesh & BGD & 0,56 \\
\hline Bolivia & BOL & 0,66 & Zambia & ZMB & 0,56 \\
\hline Iraq & IRQ & 0,66 & Kenya & $\mathrm{KEN}$ & 0,56 \\
\hline Kyrgyzstan & KGZ & 0,65 & Cambodia & KHM & 0,55 \\
\hline Tajikistan & TJK & 0,64 & Myanmar & MMR & 0,55 \\
\hline
\end{tabular}




\begin{tabular}{|l|c|c|l|c|c|}
\hline Country & ID & HDI & Country & ID & HDI \\
\hline Nicaragua & NIC & 0,63 & Nepal & NPL & 0,54 \\
Morocco & MAR & 0,63 & Angola & AGO & 0,54 \\
Guatemala & GTM & 0,62 & Pakistan & PAK & 0,54 \\
Namibia & NAM & 0,61 & Papua New Guinea & PNG & 0,53 \\
Syria & SYR & 0,60 & Cameroon & CMR & 0,52 \\
\cline { 5 - 7 } Honduras & HND & 0,60 & Average & & 0,60 \\
\hline
\end{tabular}

The very low -level group of countries and variable classes are seen on the top-left quadrant of figure 2 . These 31 countries with their HDI values are shown in table 5. Their most important characteristic is failed democracy and market economy (BTI). They are also de- scribed by failed governance with massive difficulties. Further, rudimentary market economy and very low human development, income and education levels are related classes. The averages of the bottom group are: HDI: 0.45; BTI: 4.4 (ME: 4.0; DEM: 4.8); GOV 4.4; DIF: 7.5; GNI: 9.2; and EDU: 8.7.

Table 5. Countries with Very Low HDI category

\begin{tabular}{|c|c|c|c|c|c|}
\hline Country & ID & HDI & Country & ID & HDI \\
\hline Madagascar & MDG & 0,51 & Malawi & MWI & 0,45 \\
\hline Nigeria & NGA & 0,51 & Ethiopia & ETH & 0,43 \\
\hline Tanzania & TZA & 0,50 & Guinea & GIN & 0,42 \\
\hline Lesotho & LSO & 0,50 & Eritrea & ERI & 0,42 \\
\hline Mauritania & MRT & 0,50 & Congo Democratic Republic & COD & 0,42 \\
\hline Rwanda & RWA & 0,49 & Liberia & LBR & 0,42 \\
\hline Zimbabwe & ZWE & 0,49 & Mozambique & $\mathrm{MOZ}$ & 0,41 \\
\hline Uganda & UGA & 0,49 & Mali & MLI & 0,41 \\
\hline Yemen & YEM & 0,49 & Burundi & BDI & 0,40 \\
\hline Benin & BEN & 0,49 & Sierra Leone & SLE & 0,40 \\
\hline Sudan & SDN & 0,48 & South Sudan & SSD & 0,40 \\
\hline Haiti & HTI & 0,48 & Burkina Faso & BFA & 0,39 \\
\hline Afghanistan & AFG & 0,47 & Chad & TCD & 0,38 \\
\hline Senegal & SEN & 0,47 & Central African Republic & CAF & 0,35 \\
\hline Togo & TGO & 0,47 & Niger & NER & 0,33 \\
\hline Côte d'Ivoire & CIV & 0,46 & \multicolumn{2}{|l|}{ Average } & 0,45 \\
\hline
\end{tabular}

\subsection{Multilayer Artificial Neural Network}

The multilayer perceptron (MLP) neural network (NN) built using IBM SPSS v 20 as the statistical software. We have chosen the approach based on its proven predictive ability over several classifiers, e.g., in evaluating country risk ratings [20] and in predicting student learning performance, several authors
$[21,22,23]$ ascertained the superiority of NNs over other algorithms.

The dataset of 124 countries-in-transition (total of 617 valid cases over the period 20082016) was divided into two subsets: the train set contains $70.7 \%$ of the observations, and the test set contains $29.3 \%$ (Table 6).

Table 6. Case Processing Summary

\begin{tabular}{|ll|r|r|}
\hline & & N & \multicolumn{1}{c|}{ Percent } \\
\hline \multirow{2}{*}{ Sample } & Training & 436 & $70.7 \%$ \\
& Testing & 181 & $29.3 \%$ \\
\hline
\end{tabular}




\begin{tabular}{|l|r|r|}
\hline Valid & 617 & $100.0 \%$ \\
Excluded & 0 & \\
\hline Total & 617 & \\
\hline
\end{tabular}

We used the back-propagation algorithm based on the scaled conjugated gradient and one hidden layer. The hidden layer's activation function is the hyperbolic tangent,

$$
\sigma: R^{K} \rightarrow(0,1), P_{j}=\sigma(z)_{j}=\frac{e^{z_{j}}}{\sum_{k=1}^{K} e^{z_{k}}}, \text { for } j=1, \ldots, K \text { and } z=\left(z_{1}, \ldots, z_{K}\right) \in R^{K}
$$

$\mathrm{K}$ is the number of output neurons, four in this case. The weights are updated at each step with the goal of minimizing the error function. The error function is here the cross-entropy error due to the use of softmax-activation function. The sum of the output activations equals 1 , therefore we can interpret the softmax layer as a probability distribution and the values $P_{j}$ as the estimated probabilities of the inputs' classification [21]. For the output node $\mathrm{j}$, its predicted value $P_{j}$ and the real target $E=\sum_{j=1}^{K} t_{j} \ln P_{j}$. $f: \mathrm{R} \rightarrow(-1,1), f(c)=\frac{e^{c}-e^{-c}}{e^{c}+e^{-c}}$, and the output

layer activation function is softmax,

value $t_{j}$, the cross-entropy error is

The independent variables, V1-V16, are shown in Table 1 and the dependent variable is HDI. Figure 3 shows the number of neurons in every layer, the 16 independent variables in the input layer and the four HDI categories in the output layer. We chose one hidden layer MLP and the automatic architecture selected seven neurons and the bias.

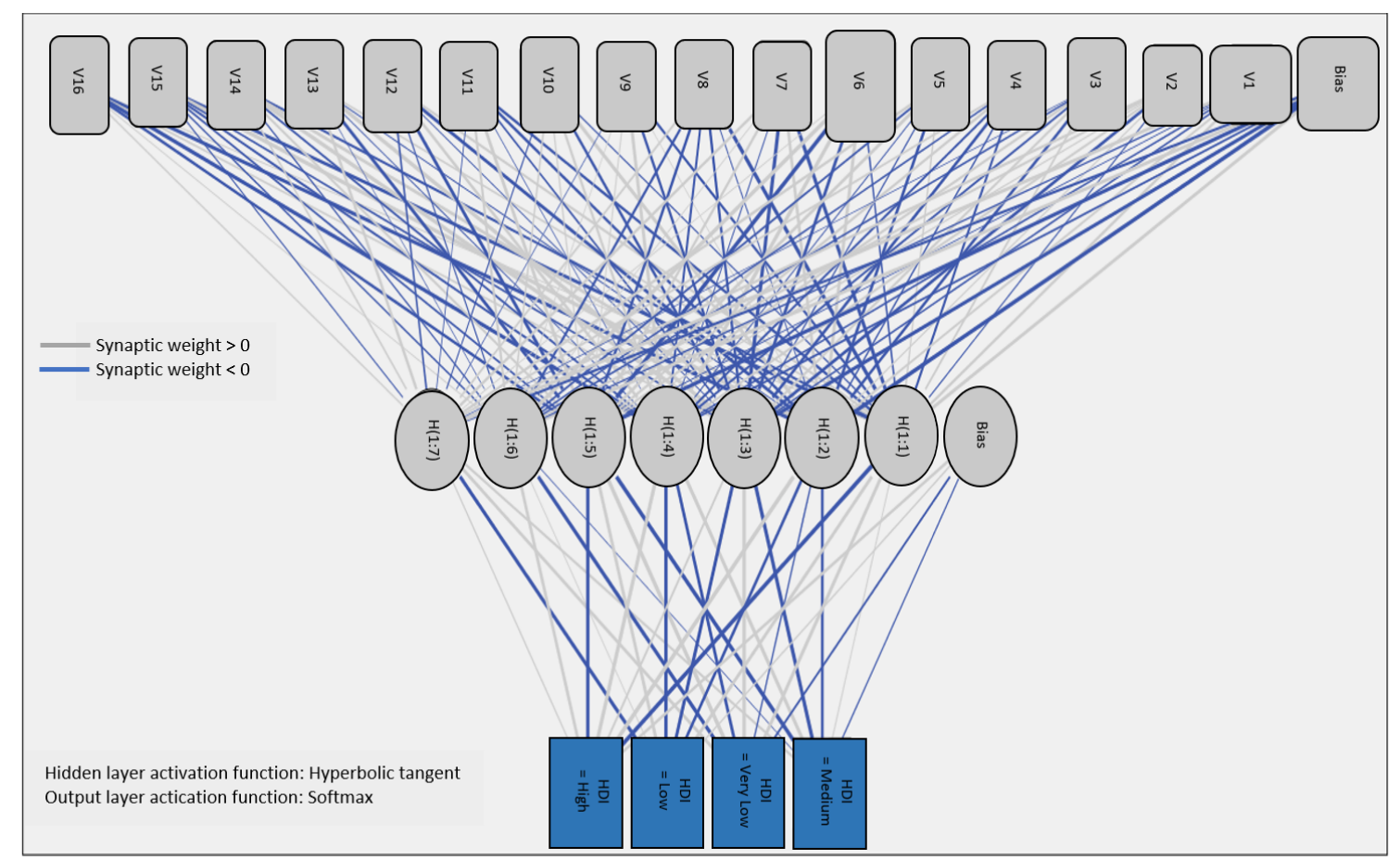

Fig. 3. The applied neural network architecture

From Figure 4, it is seen that the level of socioeconomic development (V6, particularly, socio-economic barriers), welfare regime, (V10, particularly, equal opportunities and safety nets), sustainability (V12), rule of law (V3), political and social integration (V5) and resource efficiency (V14) have the greatest effect on how MLP classifies the countries in terms of HDI categories. Other determinants of MLP predictive power are the currency and 
price stability (V8) and organization of the market and competition (V7).

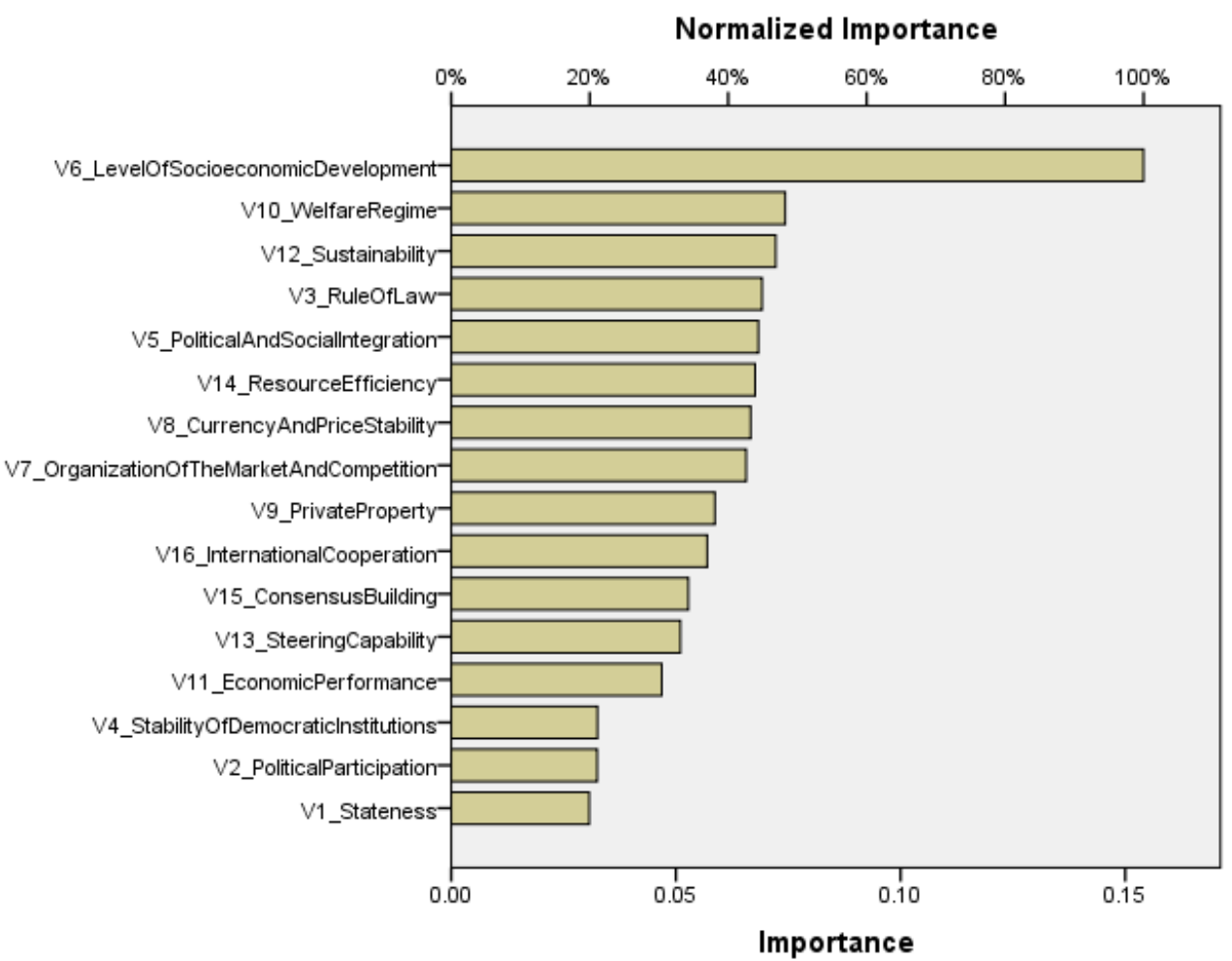

Fig. 4. The importance of factors on HDI

The model summary in Table 7 gives information about the MLP performance on the train set and the test set. The overall percentage of correct predictions of the train set and test set are $83.5 \%$ and, respectively, $85.1 \%$. MLP correctly classified.

Table 7. Classification

\begin{tabular}{|l|l|r|r|r|r|r|}
\hline \multirow{3}{*}{ Sample } & \multirow{2}{*}{ Observed } & \multicolumn{6}{|c|}{ Predicted } \\
\cline { 3 - 7 } & & Very Low & Low & Medium & High & Percent Correct \\
\hline \multirow{3}{*}{ Training } & High & 0 & 1 & 10 & 110 & $90.9 \%$ \\
& Medium & 0 & 10 & 84 & 11 & $80.0 \%$ \\
& Low & 14 & 88 & 12 & 0 & $77.2 \%$ \\
& Very Low & 82 & 13 & 1 & 0 & $85.4 \%$ \\
\cline { 2 - 7 } & Overall Percent & $22.0 \%$ & $25.7 \%$ & $24.5 \%$ & $27.8 \%$ & $\mathbf{8 3 . 5 \%}$ \\
\hline \multirow{5}{*}{ Testing } & 0 & 0 & 9 & 47 & $83.9 \%$ \\
& High & 0 & 4 & 35 & 3 & $83.3 \%$ \\
& Medium & 4 & 39 & 3 & 0 & $84.8 \%$ \\
& Low & 33 & 4 & 0 & 0 & $89.2 \%$ \\
\cline { 2 - 7 } & Very Low & & & & 0 & $\mathbf{8 5 . 1 \%}$ \\
\hline
\end{tabular}

Each predicted value is the probability that a country belongs to a class. One notices from table 7 that for wrongly predicted cases, MPL predicts a category very close to the real one, all the wrongly predicted categories in the test set have been predicted as the neighboring category or the actual one. 


\subsection{Multinomial Logistic Regression}

The model uses HDI as a class variable. HDI was conceived as a composite index combining three dimensions: education, health and income factors. Multinomial logistic regression measures the extent to which the class variable HDI depends on the set of explanatory variables, V1-V16. Each class of the dependent variable HDI leads to a probability of success. The reference class is the very low level of HDI.

Table 8. Model Fitting Information

\begin{tabular}{|l|c|c|c|c|c|c|}
\hline \multirow{2}{*}{ Model } & \multicolumn{3}{|l|}{ Model Fitting Criteria } & \multicolumn{3}{l|}{ Likelihood Ratio Tests } \\
\cline { 2 - 7 } & AIC & BIC & $\begin{array}{c}-2 \text { Log Likeli- } \\
\text { hood }\end{array}$ & Chi-Square & df & Sig. \\
\hline Intercept Only & 1709.856 & 1723.130 & 1703.856 & & & \\
\hline Final & 761.162 & 986.831 & 659.162 & 1044.693 & 48 & .000 \\
\hline
\end{tabular}

Table 8 is the likelihood ratio test of this model called Final model against the model with all parameter coefficients null called Null model. The Chi-Square statistic is 1044.663, computed as the difference between the -2 log-likelihoods of the Null and Final models. The significance level is less than 0.05 , therefore the Final model outperforms the Null model.

Table 9. Goodness-of-Fit

\begin{tabular}{|l|c|c|c|}
\hline & Chi-Square & df & Sig. \\
\hline Pearson & 1112.710 & 1800 & 1.000 \\
\hline Deviance & 659.162 & 1800 & 1.000 \\
\hline
\end{tabular}

Table 9 shows two tests of the null hypothesis according to which the model fits the data. If the null hypothesis is true, then the Pearson and deviance statistics have chi-square distributions with the degrees of freedom displayed in Table 9. The significance level equals 1, greater than 0.05 , meaning that the model fits the data.

Table 10. Pseudo R-Square

\begin{tabular}{|l|c|}
\hline Cox and Snell & .816 \\
\hline Nagelkerke & .871 \\
\hline McFadden & .613 \\
\hline
\end{tabular}

The three models from Table 10 are used to measure the coefficient of determination pseudo R-square. Nagelkerke's $R^{2}$ is the larg- est of all, 0.871 , so this model is the most appropriate: $87.1 \%$ is the proportion of variance in HDI associated with the predictors.

Table 11. Likelihood Ratio Tests

\begin{tabular}{|c|c|c|c|c|}
\hline Effect & Model Fitting Criteria & \multicolumn{3}{|c|}{ Likelihood Ratio Tests } \\
\hline & -2 Log Likelihood of Reduced Model & Chi-Square & df & Sig. \\
\hline Intercept & 731.176 & 72.014 & 3 & $\mathbf{. 0 0 0}$ \\
\hline
\end{tabular}




\begin{tabular}{|c|c|c|c|c|}
\hline V1 & 662.137 & 2.974 & 3 & .396 \\
\hline V2 & 665.763 & 6.600 & 3 & .086 \\
\hline V3 & 666.225 & 7.062 & 3 & .070 \\
\hline V4 & 661.830 & 2.667 & 3 & .446 \\
\hline V5 & 665.476 & 6.314 & 3 & .097 \\
\hline V6 & 870.765 & 211.603 & 3 & .000 \\
\hline V7 & 674.764 & 15.601 & 3 & .001 \\
\hline V8 & 678.208 & 19.045 & 3 & .000 \\
\hline V9 & 670.849 & 11.687 & 3 & .009 \\
\hline V10 & 669.649 & 10.487 & 3 & .015 \\
\hline V11 & 686.472 & 27.310 & 3 & .000 \\
\hline V12 & 669.147 & 9.985 & 3 & .019 \\
\hline V13 & 665.879 & 6.717 & 3 & .081 \\
\hline V14 & 668.518 & 9.356 & 3 & .025 \\
\hline V15 & 668.868 & 9.706 & 3 & .021 \\
\hline V16 & 677.520 & 18.357 & 3 & .000 \\
\hline
\end{tabular}

As seen in table 11, the significance value (Sig.) of the Chi-square test should be small than 0.05 , so one can conclude that significant factors om HDI are the level of socioeconomic development (V6), organization of the market and competition (V7), currency and price stability (V8), private property (V9), welfare regime (V10), economic performance (V11), sustainability (V12), V14 resource efficiency (V14), V15 consensus building (V15) and international co-operation (V16).

Table 12. Classification

\begin{tabular}{|l|r|r|r|r|r|}
\hline \multirow{2}{*}{ Observed } & \multicolumn{5}{|c|}{ Predicted } \\
\cline { 2 - 6 } & Very Low & Low & Medium & High & $\begin{array}{c}\text { Percent } \\
\text { Correct }\end{array}$ \\
\hline High & 0 & 2 & 19 & 156 & $88.1 \%$ \\
Medium & 0 & 21 & 103 & 23 & $70.1 \%$ \\
Low & 22 & 120 & 18 & 0 & $75.0 \%$ \\
Very Low & 107 & 26 & 0 & 0 & $80.5 \%$ \\
\hline Overall Percentage & $20.9 \%$ & $27.4 \%$ & $22.7 \%$ & $29.0 \%$ & $78.8 \%$ \\
\hline
\end{tabular}

We note that under the logistic regression model all the features of the political system (V1-V5), which together make up the democracy index, are insignificant (V3, rule of law, would be significant at $10 \%$ level, though) together with governance's steering capability (V13), while the governance quality (V14-V16) are significant together with all features of the economic system (V6V12).

Table 12 contains the classification results, with an overall percentage of $78.8 \%$ correct classification. The model predicts very well the countries in the top (high) and bottom (very low) HDI categories, $88.1 \%$ and $80.5 \%$, respectively, while the middle (medium and low) categories the accuracy is lower, $70.1 \%$ and $75.0 \%$, respectively.

\section{Conclusions}

This paper took a multi-method approach to study the impact of features of political and economic system on human development index, HDI over the period of 2008-2016. The purpose was to compare the effectiveness of neural network (MPL) and logistic regression in predicting the HDI classes (very low, low, medium, high) for 124 countries-in-transition and to identify the most important features 
contributing to HDI and the related aggregatelevel qualitative characteristics of countries using multiple correspondence analysis, MCA.

The MCA was run, firstly, for all countries with aggregated categorized variables of HDI, market economy, democracy, their combination, BTI, governance quality, difficulty level and GNI and education indices. The last two were included for two reasons: they are direct underlying variables in HDI and Bertelsmann use them also in their difficulty index. For the same reason, we excluded the difficulty level as it can distort the effects of political and economic features on HDI this being the main research subject. MCA suggested that higher levels of market economy, democracy and governance quality go hand-in-hand and the higher they are, the more developed the countries tend to be measured by HDI, GNI or education level.

The research literature showed in wide range of application areas that neural network can provide more accurate predictions than the more traditional statistical methods, including logistic regression models. We trained the neural network model to predict the development levels of countries-in-transition. The model had a very high rate of accuracy, $85.1 \%$. The corresponding accuracy of the logistic regression was $78.8 \%$. The identified most powerful predictors of HDI class were level of socioeconomic development (V6 reflecting socio-economic barriers), welfare regime, (V10, reflecting equal opportunities and safety nets), sustainability (V12), rule of law (V3), political and social integration (V5) and resource efficiency (V14), currency and price stability (V8) and organization of the market and competition (V7), in this order. Logistic regression gave support to the results from the $\mathrm{NN}$, but rule of law was found insignificant. The most interestingly, logistic regression didn't find any political features, V1-V5 statistically significant undermining the significance of democracy index. Regardless of the statistical insignificance in the individual political factors, the aggregate democracy level was clearly positively related to high HDI lev- els aside with market economy and governance quality, the latter also on the individual variable level.

\section{References}

[1] A. Roy,_I. Goll , "Predictors of various facets of sustainability of nations: The role of cultural and economic factors," International Business Review, vol. 23, no. 5, pp. 849-861, October 2014.

[2] N. Berggren, T. Nilsson, "Globalization and the transmission of social values: The case of tolerance, " Journal of Comparative Economics, vol. 43, no. 2, pp. 371389, May 2015.

[3] M. Buscema, P.L. Sacco and G. Ferilli, "Multidimensional Similarities at a Global Scale: An Approach to Mapping Open Society Orientations, "Social Indicators Research, vol. 128, no. 3, pp. 1239-1258, September 2016.

[4] M. Šanda and J. Křupka, "Quality of life evaluation as decision support in public administration for innovation and regions development,“ Administratie si Management Public, no. 30, pp. 51-66, 2018.

[5] R. Mickiene and E. Valioniene,"Evaluation of the interaction between the state seaport governance model and port performance indicators," Forum Scientiae Oeconomia, vol. 5, no. 3, pp. 27-43, 2017.

[6] D. Popescu Ljungholm, "Employee-employer relationships in the gig economy: harmonizing and consolidating labor regulations and safety nets," Contemporary Readings in Law and Social Justice, vol. 10, no. 1, pp. 144-150, 2018.

[7] D. Kiseláková, E. Širá and B. Šofranková, "The performance of V4 Countries according to ease of doing Business Index," Acta Oeconomica Universitatis Selye, vol. 7, no. 2, pp. $71-79,2018$.

[8] United Nations Development Programme, Human Development Report 2011, Sustainability and Equity: A Better Future for All. United Nations Publications, 2011.

[9] M. A.Salas-Bourgoin, "A proposal for a modified Human Development Index," Cepal Review, no. 112, pp. 29-44, April 2014. 
[10] V. Jurkevičius and Y. Pokhodun, "The doctrine of apparent authority as a precondition for sustainable business," Entrepreneurship and Sustainability Issues, vol. 6, no. 2, pp. 649-661, 2018.

[11] G. Ohanyan and A. Androniceanu, "Evaluation of IMF program effects on employment in the EU, "Acta Oeconomica, vol. 67, no. 3, pp. 311-332, 2017.

[12] A. Androniceanu, I. V. Drăgulănescu and M. Duca, "Economic growth and quality of life in Romania," in Proc. The 31st International Business Information Management Association Conference, vol.I, Milan, Italy, 25-26 April 2018, pp. 18621872.

[13] United Nations Development Programme (2018), Human Development Indices and Indicators: 2018 Statistical Update [Online]. New York 2018, Available: http://hdr.undp.org/sites/de-

fault/files/2018_human_development statistical update.pdf

[14] C. Binetti, "How ancient states rise and fall: pre-democratic regime typology, representation, and domestic and international balances of power," Geopolitics, History, and International Relations, vol. 10, no. 1, pp. 30-45, 2018.

[15] A. Bluszcz, "Conditions for maintaining the sustainable development level of EU member states, "Social Indicators Research,vol.139, no. 2, pp. 679-693, September 2018.

[16] A. Androniceanu, A., M. Comănescu, and I.V. Drăgulănescu, "The Impact of globalization on unemployment in Europe," in Proc. The 29th IBIMA Conference: Sustainable Economic Growth, Education Excellence, and Innovation Management through Vision 2020, vol I, Vienna, Austria 3-4 May 2017, pp. 716-724.

[17] F. G. Nunes, L. M. Martins and J. Mozzicafreddo, "The influence of service climate, identity strength, and contextual ambidexterity upon the performance of public organizations, "Administratie si Management Public, no.31, pp. 6-20, 2018.
[18] S. Mylevaganam, "The Analysis of Human Development Index (HDI) for Categorizing the Member States of the United Nations (UN)," Open Journal of Applied Sciences, vol. 7, pp. 661-690, 2017.

[19] A. Saboo, R. Parakh, P. Trivedi and M. B. Potdar, "A Comparative Study of Artificial Neural Networks and Multiple Linear Regression by Predicting Human Development Index," International Journal of Scientific \& Engineering Research, vol. 7, no. 9, pp. 424-428, 2016.

[20] Y. Yim and H. Mitchell, "Comparison of country risk models: hybrid neural networks, logit models, discriminant analysis and cluster techniques," Expert Systems with Applications, vol. 28, pp. 137-148, 2005.

[21] N. Zacharis," Predicting student academic performance in blended learning using artificial neural networks," International Journal of Artificial Intelligence and Applications, vol. 7, no. 5, pp. 17-29, September 2016.

[22] M. Paliwal and U. A. Kumar, "A study of academic performance of business school graduates using neural network and statistical techniques," Expert Systems with Applications, vol. 36, no. 4, pp. 7865-7872, 2009.

[23] C. Jayne, A. Lanitis and C. Christodoulou, "Neural network methods for one-tomany multi-valued mapping problems," Neural Computing and Applications, vol. 20, no. 6, pp. 775-785, 2011.

[24] S. Anwar and Y. Mikami, "Comparing Accuracy Preformance of ANN, MLR and GARCH Model in Predicting Time Deposit Return of Islamic Bank," International Journal of Trade, Economics and Finance, vol. 2, no. 1, pp. 44-51, Feb. 2011.

[25] A. Connoly, C.M. de Leoz, M. Gorospe and M. Sebastian, "Determinants of Having a High Human Development Index," Technical Report, pp. 1-29, 15 July 2014.

[26] A.Saboo, R. Parakh, P. Triverdi and M. B. Potdar, "A Comparative Study of Artificial Neural Networks and Multiple Lin- 
ear Regression by Predicting Human Development Index," International Journal of Scientific \& Engineering Research, Vol. 7, Issue 9, pp. 424-428, September 2016.

[27] S. Donner, H. Hartmann and R. Schwarz (2018), Transformation Index of the Bertelsmann Stiftung 2018: Codebook for
Country Assessments. [On-line] Gütersloh 2018, Available: https://www.bti-project.org/fileadmin/files/BTI/Downloads/Zusaetzliche_Downloads /BTI2018_Codebook.pdf

[28] A. Kassambara. Practical Guide to Principal Component Methods in $R$, sthda.com, 2017.

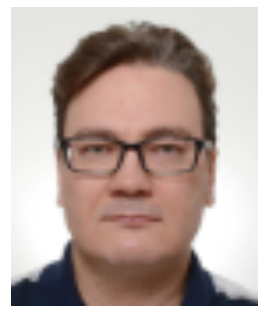

Jani KINNUNEN is a researcher at Åbo Akademi, Finland holding a MSc in Economics. His research interests include data science related to economics and political science; application work has focused on freedoms in economic and political systems, mergers and acquisitions and real options. He has about 50 publications from international conferences and journals.

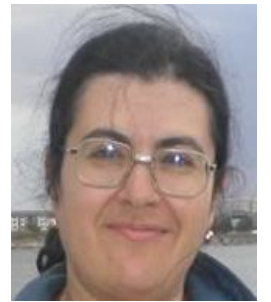

Irina GEORGESCU holds a $\mathrm{PhD}$ in Economics from Turku Centre for Computer Science, Turku, Finland. Currently she is a lecturer at the Department of Economic Informatics and Cybernetics, Bucharest Academy of Economic Studies. Her research interests lie in the areas of fuzzy sets and systems, computational intelligence and risk theory. She is the author of about 40 journal papers and 2 books published in Springer Verlag. 